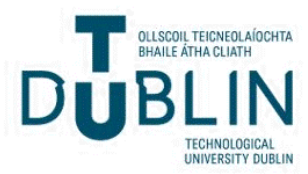

Technological University Dublin

ARROW@TU Dublin

\section{Lignocellulosic Biorefineries in Europe: Current State and Prospects}

\author{
Shady S. Hassan \\ Technological University Dublin, shady.hassan@mydit.ie \\ Gwilym A. Williams \\ Technological University Dublin \\ Amit Jaiswal \\ Technological University Dublin, amit.jaiswal@tudublin.ie
}

Follow this and additional works at: https://arrow.tudublin.ie/tfschafart

Part of the Biotechnology Commons, Economic Policy Commons, Energy Policy Commons, Environmental Policy Commons, and the Environmental Studies Commons

\section{Recommended Citation}

Shady S. Hassan, Gwilym A. Williams, Amit K. Jaiswal (2018). Lignocellulosic Biorefineries in Europe:

Current State and Prospects. Trends in Biotechnology37(3), pp.231-234 doi: 10.1016/

j.tibtech.2018.07.002

This Review is brought to you for free and open access by the School of Culinary Arts and Food Technology at ARROW@TU Dublin. It has been accepted for inclusion in Articles by an authorized administrator of ARROW@TU Dublin. For more information, please contact arrow.admin@tudublin.ie, aisling.coyne@tudublin.ie, gerard.connolly@tudublin.ie.

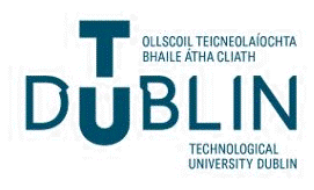




\section{Trends in Biotechnology}

CellPress

REVIEWS
Science \& Society Lignocellulosic Biorefineries in Europe: Current State and Prospects

\author{
Shady S. Hassan, ${ }^{1,2}$ \\ Gwilym A. Williams, ${ }^{2}$ and \\ Amit K. Jaiswal ${ }^{1, \star}$
}

Lignocellulosic biorefining processes plant-derived biomass into a range of bio-based products. Currently, more than 40 lignocellulosic biorefineries are operating across Europe. Here, we address the challenges and future opportunities of this nascent industry by elucidating key elements of the biorefining sector, including feedstock sourcing, processing methods, and the bioproducts market.

The Biorefinery Industry in the EU In 2012, the European Bioeconomy strategy was launched, defining the bioeconomy as the production of renewable biological resources and the conversion of these resources and waste streams into value added products'. This strategy and its action plans increased the turnover of the total bioeconomy in the European Union (EU) from €2.09 trillion in 2008 to $€ 2.29$ trillion in 2015 [1]. In the light of this development, the biorefinery is a vital component of the future bioeconomy defined by the International Energy Agency (IEA Bioenergy -Task 42, 2009) as 'an integrated production plant using biomass feedstock to produce a range of value-added products'. In 2017, there were 224 biorefineries operating across Europe, in addition to several under construction [2]. However, 181 of these commercial biorefineries are so-called 'firstgeneration' facilities, which use feedstocks such as sugar, starch, oils, and fats, and produce mainly biofuels and products of oleochemistry. Conversely, only 43 biorefineries are so-called 'second-generation' facilities, which use more sustainable lignocellulosic feedstocks, such as nonfood and nonenergy crops and biowaste, to produce biofuel, electricity, heat, bio-based chemicals, and biomaterials. Fast-paced regulatory developments in the EU are accelerating the rate of lignocellulosic exploitation. For example, EU Directive 2015/1513 set out targets for a maximum of $7 \%$ share of biofuels to be derived from cereals, starch, sugars, and oil-bearing crops by 2020 (including those grown for energy purposes on agricultural land). Additionally, in January 2018, the European Parliament voted to limit its support for biofuels made from food crops, aiming to gradually reduce such fuels to $3.8 \%$ by 2030; ancillary measures seek to exclude palm oil-derived biofuels from the list of products that can count towards renewable targets by 2021, and to incentivize the use of lignocellulosic wastes in biofuel production. The EU has funded many projects under Horizon 2020 (the EU Research and Innovation program that manages $\sim € 80$ billion of research funding over the 7-year period from 2014 to 2020) to stimulate the use of various lignocellulosic feedstocks, with the aim of consolidating lignocellulosicbased biorefineries in Europe (Table 1). Therefore, a critical assessment of the future of the lignocellulosic biorefinery concept against a background of the current biorefining industry is especially timely.

\section{The Workflow of the Biorefining} Industry

Lignocellulosic Feedstock Supply

Many different raw materials can be used as feedstocks for a lignocellulosic biorefinery, from residues derived from forestry or agriculture to agroindustrial wastes. The current annual consumption of lignocellulosic biomass in bio-based industries, compared with the total biomass availability, is relatively small. Even future projections, such as estimates outlined in the S2Biom project (which aims to predict the sustainable nonfood biomass potential at the EU level), have predicted a maximum requirement of 476 million tons of lignocellulosic biomass to fulfil the needs of all biobased industry in Europe by 2030. To put this into perspective, at least 1 billion tons of lignocellulosic biomass will be produced in Europe on an annual basis by 2030 [3]. Therefore, the challenge is not the availability of feedstock, but rather the logistical challenge surrounding the feedstock supply. The lignocellulosic feedstock supply chain may encompass collection, drying, densification, transport, and storage, and such processes will vary depending on biomass type and source [4-6]. Each supply chain stage faces formidable challenges, summarized below.

\section{Collection}

The greatest challenges in the collection process are the marked decentralization of sources, the unpredictable fluctuations in quantity and quality, high moisture content (e.g., in the case of agroindustrial waste), and possible contamination (e. g., soil pollution in agricultural residues). Collection, drying, and densification are conducted in decentralized facilities before transportation to the biorefinery or centralized storage facility.

\section{Drying}

Lignocellulosic biomass derived from agroindustrial wastes or residues contains a high level of moisture, which may complicate biomass handling, size reduction, and densification, as well as increasing the susceptibility of biomass to spoilage and a consequent rapid deterioration in quality. Drying processes may be natural (e.g., in the case of grasses) or conducted via conventional heating or microwaves. 


\section{Trends in Biotechnology}

Table 1. Projects Funded by the EU for Utilizing Lignocellulosic Feedstocks in the Biorefinery Industry

\begin{tabular}{|c|c|c|c|c|}
\hline Project name & Biorefinery feedstock & Country coordinated in & Period & Total cost $(€)$ \\
\hline AgriChemWhey & Byproducts from dairy processing & Ireland & 2018-2021 & 29949323 \\
\hline GRACE & Miscanthus or hemp varieties from marginal lands & Germany & 2017-2022 & 1500085121 \\
\hline SmartLi & Kraft lignins, lignosulfonates, and bleaching effluents & Finland & 2015-2019 & 240746125 \\
\hline $\mathrm{BIOSKOH}$ & Lignocellulosic feedstock & Italy & 2016-2021 & 3012231375 \\
\hline BARBARA & Agri and food waste & Spain & $2017-2020$ & 2711375 \\
\hline AgriMax & Agri and food waste & Spain & 2016-2020 & 1554349456 \\
\hline PULP2VALUE & Sugarbeet pulp & Netherlands & 2015-2019 & 1142834750 \\
\hline GreenSolRes & Lignocellulosic residues or wastes & Netherlands & 2016-2020 & 1060963701 \\
\hline Dendromass4Europe & Dendromass on marginal land & Germany & 2017-2022 & 2044231875 \\
\hline SYLFEED & Wood residues & France & $2017-2020$ & 14976590 \\
\hline GreenProtein & Vegetable residues from packed salad processing & Netherlands & 2016-2021 & 554651999 \\
\hline PROMINENT & Cereal processing side streams & Finland & 2015-2018 & 310389750 \\
\hline FIRST2RUN & Cardoon from marginal lands & Italy & 2015-2019 & 2502268875 \\
\hline Zelcor & $\begin{array}{l}\text { Lignocellulosic residues from ethanol production, lignins dissolved during } \\
\text { pulping process, and lignin-like humins formed by sugar conversion }\end{array}$ & France & 2016-2020 & 671001250 \\
\hline STAR4BBI & Lignocellulosic feedstocks from forests and agriculture & Netherlands & 2016-2019 & 99587750 \\
\hline BIOrescue & Wheat straw and agroindustrial waste & Spain & 2016-2019 & 376758750 \\
\hline OPTISOCHEM & Residual wheat straw & France & $2017-2021$ & 1637681683 \\
\hline US4GREENCHEM & Lignocellulosic feedstock & Germany & 2015-2019 & 3803925 \\
\hline FUNGUSCHAIN & Mushroom (Agaricus bisporus) farming residues & Netherlands & 2016-2020 & 814366125 \\
\hline POLYBIOSKIN & Food waste & Spain & $2017-2020$ & 405835938 \\
\hline ValChem & Woody feedstock & Finland & 2015-2019 & 1850270325 \\
\hline LIBBIO & Andes lupin from marginal lands & Iceland & 2016-2020 & 4923750 \\
\hline LIGNOFLAG & Straw & Germany & 2017-2022 & 34969215 \\
\hline
\end{tabular}

\section{Densification}

Densification (compaction), carried out by means of stacking, baling, briquetting, or pelletizing, is an essential preprocessing step to increase the bulk density of lignocellulosic materials. These steps permit efficient transport and storage operations and achieve standard sizes and weights for each unit of feedstock. Before the compacting process, mechanical processing may be required to reduce size by shredding and grinding. While existing equipment used in agriculture could be used in moderate-scale biomass compacting and size reduction, new technologies are required to handle large amounts of biomass for industrial-scale processing.

Transport

Economically, transportation efficiency is increased when the collection area is closer to the processing and/or storage facility. Existing transportation systems used for moving woodchips or lignocellulosic wastes may prove inefficient due to the low density of lignocellulosic wastes and transportation energy costs.

\section{Storage}

Variations in quantity and seasonal availability of agricultural residues or agroindustrial waste, as well as in the location of sources, all combine to create the need for long-term storage facilities. However, this requirement presents challenges in terms of maintaining biomass quality at a high capacity and at a low cost. Additionally, there may be significant health and safety aspects of biomass storage that can complicate operations [7].

\section{Addressing the Challenges}

To address these challenges in supply chain logistics, several strategic research initiatives have been recommended by or the European Biorefinery Joint Strategic 


\section{Trends in Biotechnology}

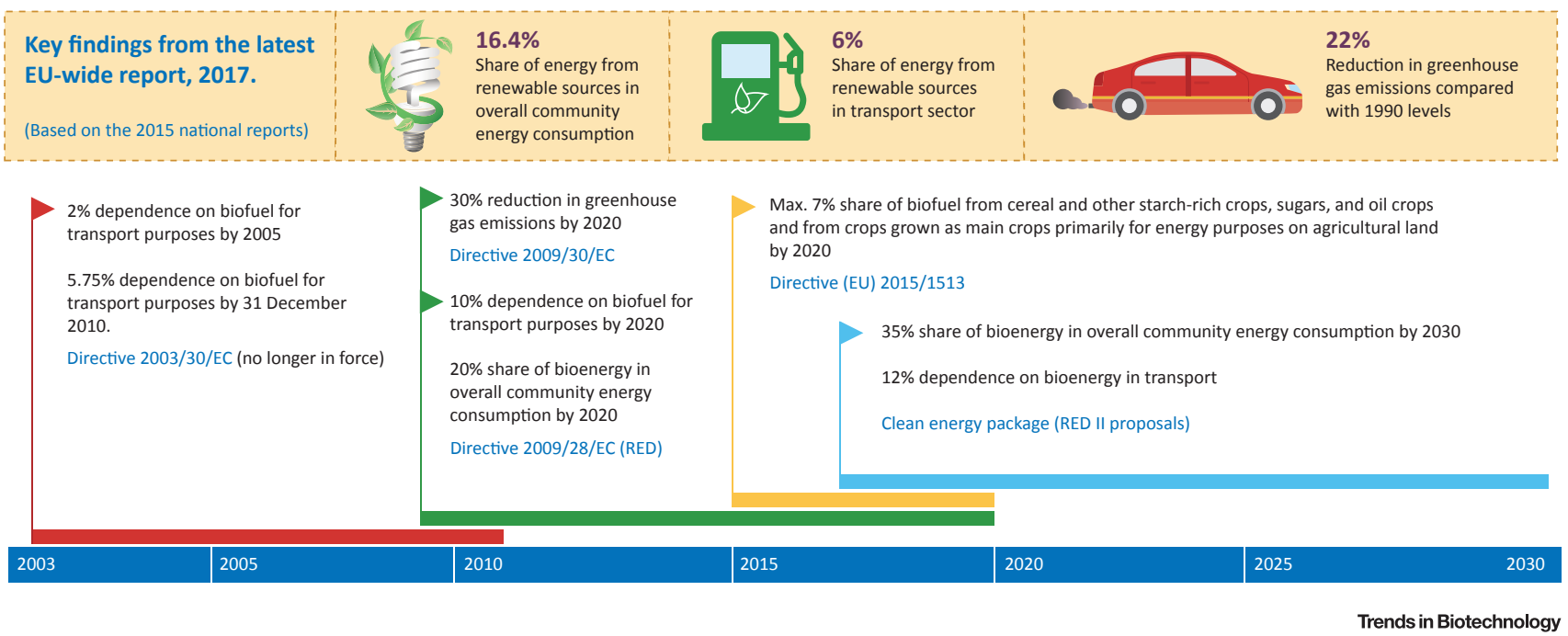

Figure 1. Biofuel Policy and Targets from 2003 to 2018 and a Road Map for 2020 and Beyond. Abbreviation: EU, European Union.

Research Roadmap for 2020, with a view to achieving the European Biorefinery 2030 vision [8]. Such recommendations include the development of integrated logistical models to remove supply chain bottlenecks, the availability of machinery that is capable of handling large amounts of feedstock, the mapping of biomass inventories, and the establishment of a centralized regional hub for biomass collection and storage.

These efforts are expected to decrease logistical costs, which in turn may reduce biorefinery production costs. However, for long-term commercial success, economies of scale in terms of biorefinery size are also vital in the goal to achieve economically acceptable conversion processes [9]. Thus, logistics costs and operational complexity increase as processing capacity or lignocellulosic feedstock collection and/or storage radius increase. Accordingly, smaller scale integrated biorefinery units are being studied for suitability in small rural-urban areas in Europe to address these challenges [10].

\section{Processing of Lignocellulosic Feedstock}

Lignocellulosic biomass is a complex matrix that is relatively refractory to degradation. Sugars are locked in a recalcitrant structure that requires a pretreatment step to release them. Many conventional methods (e.g., chemical, physical, and biological methods) are currently used to pretreat lignocellulosic biomass. However, achieving a workable balance between pretreatment efficacy, cost, and environmental sustainability is difficult [11]. Therefore, even combinations of these methods have not been deployed effectively at the required scale of an integrated biorefinery that utilizes multiple feedstocks.

The current mainstream lignocellulose disruption technologies that are used in a typical biorefinery depend both on the specific lignocellulosic feedstock and the value of the final product. Such technologies may be classified as either biochemical [12] or thermochemical [13], and key challenges relate to scalability and flexibility to sustainably optimize the production process (against a background of diverse feedstocks, variable market demand, and fluctuating economics). Hence, integrating the biorefinery concept with existing industrial processing methods has been identified as a potential solution to address these challenges. For example, the most common proposed model cited is an integrated biorefinery-pulp/paper plant that can produce chemicals, fuels, or electric power, along with conventional wood, pulp, and paper products. However, in reality, aspects such as the separation and purification of products, as well as ensuring quality and standardization, add additional challenges to the industrialization process.

\section{The Bio-Based Products Market}

Examples of potential bio-based products include biofuels (e.g., bioethanol, biodiesel, and biogas), biochemicals (e.g., industrial enzymes and nutraceuticals), and biomaterials (e.g., biodegradable plastics) [14]. However, supported by specific EU policies (Figure 1), bioenergy and biofuels have received greater attention. By the year 2030 , the EU aims to provide $25 \%$ of its 


\section{Trends in Biotechnology}

CellPress

REVIEWS transportation energy via biofuels derived from advanced biorefineries (second-generation biorefineries). By this time, it also intends to replace $30 \%$ of oil-based chemicals with bio-based chemicals and supplant nondegradable materials with degradable materials. Interestingly, 80\% of the EU bio-based infrastructure will be in rural areas, which are expected to support community development programs. However, developing sustainable markets for bio-based products, and raising the public awareness of this area will remain a challenge. Even so, it is expected that evolving market demand, combined with further EU policies acting to spur public awareness, will accelerate product development and encourage private sector investment. International experts foresee that at least 15 advanced biorefineries will be launched by 2024 [15].

\section{Concluding Remarks}

The lignocellulosic biorefinery represents an important component of the future European bioeconomy. While this nascent industry faces significant challenges, such as feedstock logistics, limitations of conventional processing technologies, and uncertain market economics, such challenges are being countered by ambitious EU policies that are aimed at supporting this industry to achieve climate and bioenergy goals.

\section{Acknowledgment}

The authors would like to acknowledge funding from Dublin Institute of Technology (Ireland) under the Fiosraigh Scholarship program, 2017.

${ }^{1}$ School of Food Science and Environmental Health, College of Sciences and Health, Dublin Institute of Technology, Cathal Brugha Street, Dublin 1, Ireland ${ }^{2}$ School of Biological Sciences, College of Sciences and Health, Dublin Institute of Technology, Kevin Street, Dublin 8, Ireland

${ }^{*}$ Correspondence:

amit.jaiswal@dit.ie, akjaiswal@outlook.com (A.K. Jaiswal). https://doi.org/10.1016/j.tibtech.2018.07.002

References

1. Piotrowski, S. et al. (2018) European Bioeconomy in Figures 2008 - 2015, Nova Institute for Ecology and Innovation

2. Nova-Institut GmbH and Bio-based Industries Consortium (2017) Map of 224 European Biorefineries Published by BIC and Nova-Institute, Bio-Based News
3. S2Biom (2016) Vision for 1 Billion Dry Tonnes Lignocellulosic Biomass as a Contribution to Biobased Economy by 2030 in Europe, S2Biom

4. Seebaluck, V. and Leal, M. (2015) Feedstock supply chains. In Bioenergy \& Sustainability: Bridging the Gaps (Souza, G. et al., eds), pp. 348-367, Scientific Committee on Problems of the Environment

5. US Department of Energy (2015) Advancing Systems and Technologies to Produce Cleaner Fuels, US Department of Energy

6. Annevelink, B. et al. (2014) D3.1 Review of the Main Logistical Components, S2Biom

7. Koppejan, J. et al. (2013) Health and Safety Aspects of Solid Biomass Storage, Transportation and feeding, IEA Bioenergy

8. Star-COLIBRI (2011) European Biorefinery Joint Strategic Research Roadmap for 2020, Star-COLIBR

9. Wang, Y. et al. (2017) Impact of the biorefinery size on the logistics of corn stover supply - a scenario analysis. Appl. Energy 198, 360-376

10. Susmozas, A. et al. (2017) Report on Selection of Business Case Studies, SimBio

11. Hassan, S.S. et al. (2018) Emerging technologies for the pretreatment of lignocellulosic biomass. Bioresour. Technol. J. 262, 310-318

12. US Department of Energy (2013) Biochemical Conversion: Using Hydrolysis, Fermentation, and Catalysis to Make Fuels and Chemicals, US Department of Energy

13. Tanger, P. et al. (2013) Biomass for thermochemical conversion: targets and challenges. Front. Plant Sci. 2013, 4

14. Ravindran, R. and Jaiswal, A.K. (2016) Exploitation of food industry waste for high-value products. Trends Biotechnol. 34, 58-69

15. Valdivia, M. etal. (2016) Biofuels 2020: biorefineries based on lignocellulosic materials. Microb. Biotechnol. 9, 585-594 